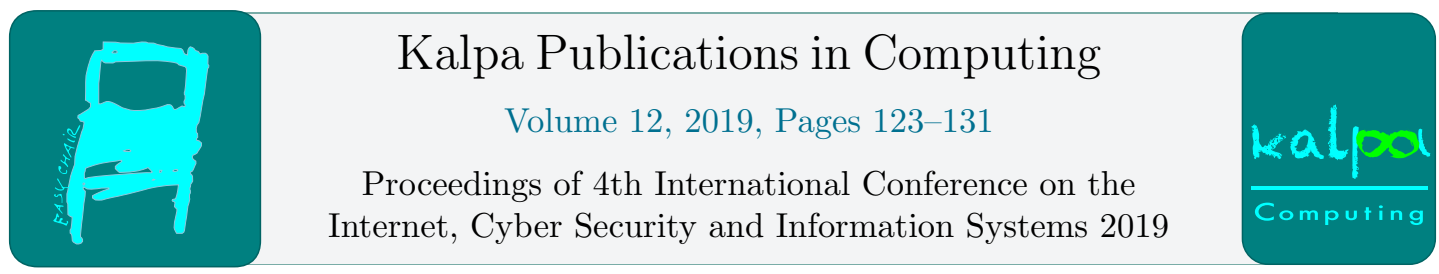

\title{
A Conceptual Model for Institutional Adoption of Learning Technologies in Higher Education
}

\author{
Mncedisi Chris Mabhele ${ }^{1}$ and Jean-Paul Van Belle ${ }^{2}$ \\ ${ }^{1}$ University of Cape Town, Cape Town, RSA \\ ${ }^{1}$ mbhmnc001@myuct.ac.za, ${ }^{2}$ jean-paul.vanbel le@uct.ac.za
}

\begin{abstract}
As learning technologies advance and become more ubiquitous, particularly in elearning, new opportunities are emerging for higher education institutions to address significant academic and administrative challenges. Driven by increasing competition, changing environments and other market forces, institutions are considering learning technologies in order to thrive and remain relevant. This study gathered insights from existing literature to propose a conceptual model that supports decision making in the adoption of learning technologies by higher education institutions. The conceptual model adopts the Transformative Framework for Learning Innovation as its foundation and superimposes the Emerging Learning Technologies Model. The resulting model provides a clear guidance for higher education institution to achieve five key learning characteristics. This paper found that combining these two approaches provides a logical approach for higher education institutions to address organisational, strategic and learning-specific dimensions in a coherent format. Furthermore, academics and practitioners can benefit from valuable insights in the proposed alternative approach to learning technology adoption.
\end{abstract}

\section{Introduction}

The education sector is currently undergoing a massive and significant transformation, comparable to the 19th century dawn of universal schooling (Collins \& Halverson, 2018). This transformation is underpinned by technology advancement (Delgado, Wardlow, O’Malley, \& McKnight, 2015), particularly in the form of e-learning technologies (Li, Wong, Cheung, Lam, \& Ng, 2014) and technology-enhanced learning (TEL) (Bälter, 2017). Whilst the future of e-learning is promising (King \& Boyatt, 2014), it still needs to overcome reputational and quality hurdles to prove itself (Bälter, 2017).

In the context of this study, learning technologies refer to technology innovations that are already mainstream and currently being used to support learning, particularly in higher education (Isaías, 2018). E-learning refers to the use of ICT in the enhancement and support of learning and teaching in education 
(OECD, 2019). TEL extends the application of e-learning, and includes the enhancement of classrooms through learning with technology (Gordon, 2014). The use of technology by higher education institutions in improving outcomes still remains a challenge (Hill, Guthrie, \& Kurzweil, 2018). There is a gap in how pedagogical innovation, combined with these technologies affect the future of society (Canals, Burkle, \& Nørgård, 2019). Furthermore, institutions are challenged with harnessing technology power as a means to accelerated access to education and improved overall success (Hill et al., 2018).

Leadership plays a critical role in the acceptance, adoption and continued use of learning technologies in higher education institutions. Akcil, Aksal, Mukhametzyanova and Gazi (2017) identify technology self-efficacy and acceptance in leadership as influential in driving digital citizenship in the education system. Similarly, Bälter (2017) identifies leadership that instils cooperation between crossdisciplinary areas as critical in improving technology acceptance in higher education. A leadership that develops an innovation driven culture and infrastructure also supports adoption of e-learning within the organisation (King \& Boyatt, 2014).

Various trends have shaped learning technologies in the past five years. The wider adoption of Massive Open Online Courses (MOOCs) (Tseng, Tsao, Yu, Chan, \& Lai, 2016; Daniel, Cano, \& Cervera, 2015), Open Educational Resources (OERs) (Sandanayake, 2019) and Learning Management Systems (LMS) (Oliveira, Cunha, \& Nakayama, 2016) have propelled e-learning to be one of the main agenda items for higher education leadership. MOOCs are massive in terms of number of concurrent learners they accommodate, usually for free and delivered online. OERs seek to increase public access to educational resources through open license and/or free access (Sandanayake, 2019).

An institution's existing infrastructure, expectations from students and skills/attitudes of staff members are some of the main drivers of e-learning adoption in higher education institutions (King \& Boyatt, 2014). In the next five years and beyond, leadership will continue to play a role in the adoption of learning technologies within higher education institutions. Amongst others, learning technologies will be driven by greater adoption of adaptive learning (Truong, 2016), microlearning (Giurgiu, 2017) and gamification (Majuri, Koivisto, \& Hamari, 2018). These are complex interventions that need to be properly thought through by leadership. This paper proposes a conceptual model for the adoption of learning technologies in higher education institutions.

\section{Literature Review}

Adoption of technology has traditionally been slow in the higher education sector (Salmon, 2014). Some of the factors that hinder e-learning adoption include existing infrastructure, anticipated learner needs and capabilities of staff (King \& Boyatt, 2014). On the other hand, drivers such as competitive market places, the need to reduce costs against the backdrop of increasing student expectations are driving the need for technology adoption (Salmon, 2014).

In order for institutions to be sustainable and scale up in the digital age, inclusion of innovation in the organisation strategy is crucial (Salmon, 2014). To justify the need for better framework for adopting innovations, this study illustrates recent e-learning developments that are impacting the higher education sector.

From the literature reviewed, six emerging technology themes are appearing more consistently than others. These are adaptive learning, microlearning, gamification, learning analytics, artificial intelligence and ubiquitous learning (International, Analytics, \& Conference, 2016; Isaías, 2018; Salmon, 2014; Sclater, Peasgood, \& Mullan, 2016).This section discusses these themes and their potential impact in higher education. 


\subsection{Adaptive Learning}

People's learning styles differ. Whilst some might find technical concepts easy to grasp, others might be challenged by the same material. Adaptive learning intends to personalise the learning experience in order to cater for an individual's learning style (Truong, 2016). Learning environments that take learning style influence yield positive achievement results for students (Özyurt \& Özyurt, 2015). Isaías (2018) predicts that by 2020 adaptive learning will be a leading strategy driver in delivering personalisation. Whilst adaptive learning receives positive reviews from targeted research respondents, its application on assessment is still at infancy stage (Truong, 2016).

\subsection{Microlearning}

Microlearning breaks up learning material into bite-sized chunks in an effort to help the learner achieve a specific objective (Giurgiu, 2017). Microlearning provides learner-centricity, accessibility while reducing the time it takes to put together learning material (Giurgiu, 2017). The advantages of microlearning include little effort required from learning sessions, high potential for engagement and informal learning context (Jomah, Amamer, Kishore, \& Aurelia, 2016a). Microlearning has the potential to increase retention of information by $20 \%$ (Giurgiu, 2017). Microlearning has limitations such as its unsuitability in complex learning scenarios. As it inherits from an informal disposition, it can be easily perceived as less impactful (Jomah, Amamer, Kishore, \& Aurelia, 2016b).

\subsection{Gamification}

Gamification in learning refers to the application of gaming techniques in support of different activities and behaviours in the learning experience (Gordon, 2014). Gamification enhances student engagement on learning content that leads to anticipated behaviour change (Rai \& Chunrao, 2016). Using behavioural science principles, gamification increases the motivation and involvement of users in learning content (Isaías, 2018). Popular affordances where gamification has been applied include achievement/progression, immersion and social cooperation features (Majuri et al., 2018). One of the drawbacks of gamification is the cost of developing effective gamified content (Majuri et al., 2018).

\subsection{Learning Analytics}

Using a wide range of learner data and information, learning analytics aims to provide deep insights into learner behaviour, progress and learning contexts with the aim of improving learning (Sclater, Peasgood, \& Mullan, 2016). Learning analytics enable teachers to understand their learners better, resulting in better usage of already stretched resources (Clow, 2013). Implemented successfully, learning analytics are expected to make contributions in quality improvement and assurance, increasing student retention rates, improving assessments and enabling other e-learning innovations (Sclater et al., 2016). Learning analytics have a long way to go. Gašević, Dawson and Siemens (2015) argue that for learning analytics to be effective, it needs to leverage off existing learning and teaching body of research knowledge. Also, ethics and privacy concerns are considerations in the future of learning analytics. Drachsler and Greller (2016) highlight data misuse, cyber-attacks and commercial interests as ethics and privacy concerns to be considered.

\subsection{Artificial Intelligence in learning}

AI algorithms are a promising avenue in the delivery of individualised instruction, whilst AI tutoring is helping to reduce the burden on teachers by helping in assessments and providing student support (Adams Becker et al., 2017). AI will also play a role in self-learning interventions that will play a role 
in personalising the learner experience (Ustundag \& Cevikcan, 2017). Isaías (2018) predicts that AI will be widely implemented for the mainstream users within this decade.

\subsection{Ubiquitous Learning}

Ubiquitous learning enable the learning process to transcend geographic and time limits, allowing students to learn anywhere and anytime (Isaías, 2018). Mobile learning is experiencing unprecedented growth that is fuelling ubiquitous learning (Adams Becker et al., 2017). Advancing mobile technology and the increasing number of students using mobile devices will make mobile learning a key element of education strategy for higher education institutions (Isaías, 2018).

This list of technologies is not exhaustive, but merely highlights some of the key technologies that are shaping the industry now. Other technologies such as Virtual and Augment Reality, Internet of Things and Social Learning are also worth noting. However, due to space limitations, this paper does not cover these technologies. The next topic discusses the model and framework that support the adoption of these technologies.

\section{Theoretical Foundation}

This section discusses the theoretical foundations that have contributed to the proposed conceptual model in this study. There are various theories that are useful in the study of learning technology adoption, such as the Innovation Diffusion Theory, the Technology Acceptance Model (TAM), the United Theory of Acceptance and Use of Technology (UTAUT) and the Concerns-Based Adoption Model (Straub, 2009). The Transformative Framework for Learning Innovation (Salmon, 2014) and the Emerging Learning Technologies Model (Isaías, 2018) are more specific to the emergent dimension of learning technologies and thus best suited for this study.

\subsection{The Transformative Framework for Learning Innovation}

The Transformative Framework for Learning Innovation (TFLI) is a strategy-based conceptual model that considers a relationship between an institution's internal resources and skills against its environment's opportunities and risks (Salmon, 2014). TFLI advocates for innovation choices to be based on the ability of technology to meet institutional objectives (Salmon, 2014). Using four quadrants, TFLI categorises technology adoption strategies according to market/mission objectives and newness of technology. Error! Reference source not found. outlines TFLI and its four 
quadrants.

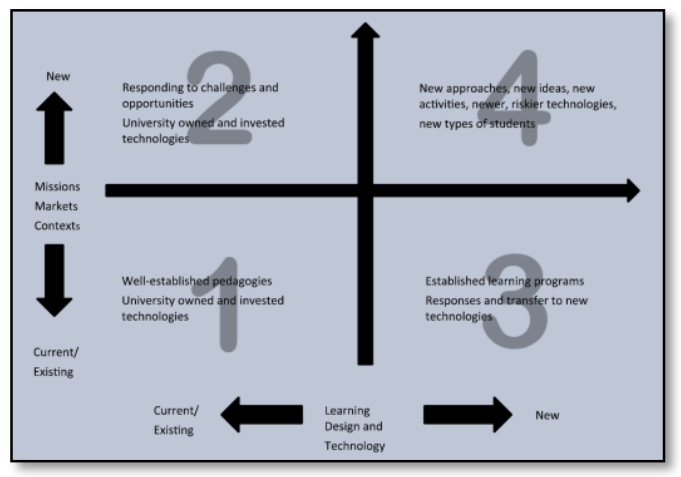

Figure 1: The Transformative Framework for Learning Innovation (Salmon, 2014)

According to Salmon (2014),

Quadrant 1 (Existing capabilities) leverages an institution's current core infrastructure and processes by infusing them into new teaching and learning opportunities. Whilst this is a slow evolutionary approach, it increases pedagogical soundness. This quadrant can ensure equal distribution of services and learning experiences for every student irrespective of location.

Quadrant 2 (New missions and markets) continues leveraging current technologies and pedagogies but seeks to address new and different learning and teaching opportunities. This quadrant allows the institution to significantly increase uptake and expand geographically. It also creates a possibility for full digital delivery or online-only platforms.

Quadrant 3 (New technologies and existing missions) addresses existing missions by employing new technologies. Most of these technologies are not necessarily developed for teaching and learning, but they get adapted to this environment. Others, such as MOOCs and OERs are built for educational use cases from the ground up.

Quadrant 4 (New missions and new technologies) pushes the boundaries by addressing new opportunities through employment of new ideas, riskier technologies and new types of students. This quadrant extends the biggest potential for placing the institution on the digital map. On the other side, this quadrant requires a technology leader approach. Technologies such gamification, machine learning, augmented reality currently reside in this quadrant.

\subsection{Emerging Learning Technologies Model}

Using the Emerging Learning Technologies Model (ELTM), Isaías (2018) claims that "emerging technologies should be selected and implemented to attain five core characteristics of learning: personalised, ubiquitous, collaborative, lifelong and authentic" (p. 405). There is a growing demand for personalisation in learning (Ng'ambi, Brown, Bozalek, Gachago, \& Wood, 2016). Becker et al. (2017) identify ubiquitous, collaborative and learning as key drivers in learning. Lifelong learning also continues to be a growing trend (Atiaja \& Guerrero, 2016). Error! Reference source not found. breaks down the technologies that make up ELTM. The list of technologies is not exhaustive, they rather present scaffolding capacity for further learning attributes (Isaías, 2018). 
The framework and model discussed above provide a legitimate context from which higher

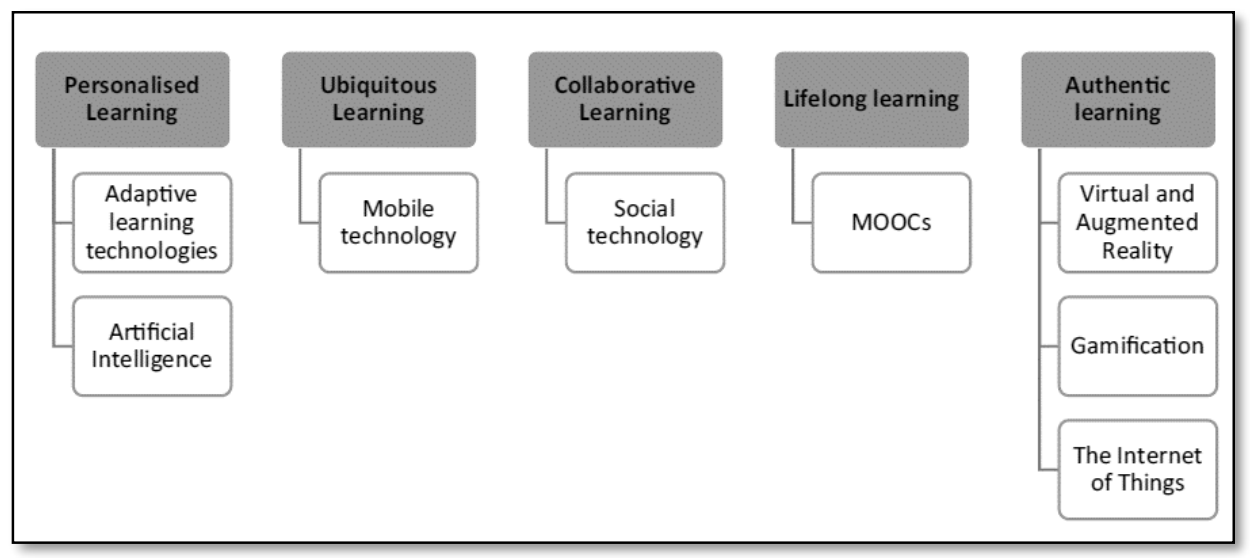

Figure 2: The emerging learning technologies model (Isaías, 2018)

education institutions can make meaningful adoption decisions. However, these tools come from disparate viewpoints. The following section proposes combining the framework and model into a comprehensive model.

\section{The Conceptual Model}

The proposed conceptual model super imposes ELTM on top of TFLI. This approach provides higher education institutions with a clearer context of the types of technologies to consider against organisational contexts and/or objectives. The model follows the same quadrant principle as TFLI. It then meaningfully allocates the core characteristics and respective technologies identified by ELTM into the quadrants. This significantly improves understanding for decision makers.

Whilst TFLI provides a quadrant approach, upon which to classify technology types by maturity and organisational mission/contexts, ELTM provides a context that is driven by learning objectives. Combining these two approaches provides a logical approach for higher education institutions to address organisational, strategic and learning-specific dimensions in a coherent format.

Error! Reference source not found. outlines the proposed conceptual model. 


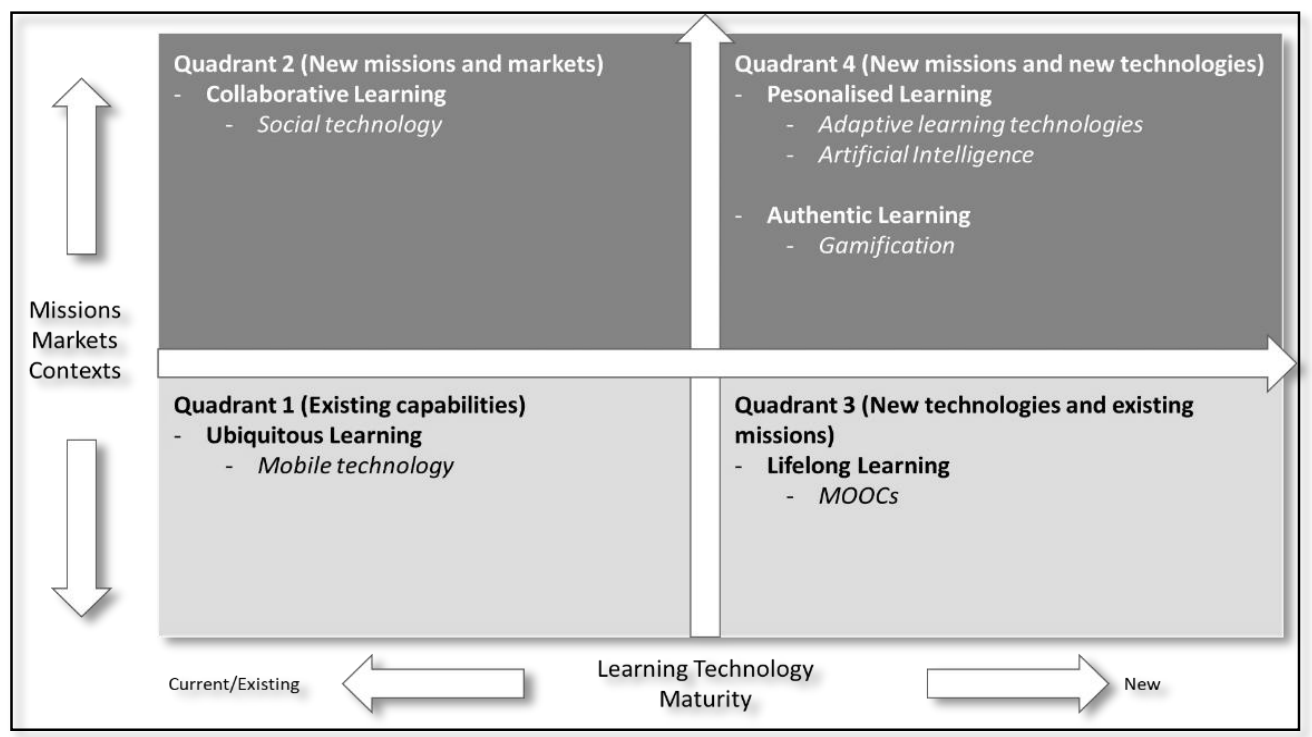

Figure 3: The proposed conceptual model

Quadrant 1 is made up of technologies that fit within existing institutional capabilities and current missions. Ubiquitous learning is currently part of institutional missions and leverages off existing infrastucture in the form of mobile technology (Isaías, 2018). Therefore, ubiquitous learning logically fits in quadrant 1. On the other hand, the influence of social technology in knowledge sharing and educational networking plays a role in collaborative learning (Isaías, 2018). Whilst social technology is within existing institutional technology capabilities, it is geared towards new markets and therefore resides in quadrant 2. Technologies that provide opportunities for lifelong learning, particularly in the form of MOOCs are a recent frontier for higher education institutions (Sclater et al., 2016). However, MOOCs address the existing mission of continuous learning, and as a result fit in quadrant 3 . Finally, quadrant 4 is made up new technologies that address new missions. This is the realm of personalised and authentic learning. Technologies such as adaptive learning, artificial intelligence and gamification fit in this quadrant.

This conceptual model gives a clearer guide on the prioritisation of technologies against the nature of missions, markets and/or contexts that an institution seeks to address. Using this model, an institution can choose a relevant strategic path to take in addressing its approach to the abundance of learning technologies currently available. The model also allows a multi-quadrant approach, whereby a single institution can have sub-strategic objectives that fit in more than one quadrant at the same time. For an example, an institution might be entrenching more off-campus learning (quadrant 1), whilst at the same improving personalization of learning (quadrant 4).

\section{Conclusion}

Highlighting five major learning technologies, together with two opportunities in the current higher education environment, this paper highlights the forces that are driving the industry. Technology will continue to be a key driver in the advancement of education well into the future. Moreover, the current technologies are constantly improving and giving rise to new applications. 
Higher education institutions remain with the challenge of carefully selecting and adopting suitable technologies in their contexts. This paper proposed a model to assist in this task. The four quadrants contextualise the institution's current and desired mission/market states. The superimposed core learning characteristics assist institution in finding a practical roadmap for making the most meaningful technology choices. The model is adaptable as technologies evolve and new ones are introduced.

\section{References}

Adams Becker, S., Cummins, M., Davis, A., Freeman, A., Hall Giesinger, C., \& Ananthanarayanan, V. (2017). NMC Horizon Report: 2017 Higher Education Edition. Austin, Texas: The New Media Consortium.

Akcil, U., Aksal, F. A., Mukhametzyanova, F. S., \& Gazi, Z. A. (2017). An examination of open and technology leadership in managerial practices of education system. EURASIA Journal of Mathematics Science and Technology Education, 13(1), 119-131. https://doi.org/10.12973/eurasia.2017.00607a

Atiaja, L. N. A., \& Guerrero, R. S. (2016). The MOOCs: Origin, characterization, principal problems and challenges in Higher Education. Journal of E-Learning and Knowledge Society, 12(1), 65-76.

Bälter, O. (2017). Moving Technology-Enhanced-Learning forward: Bridging divides through leadership. International Review of Research in Open and Distributed Learning, 18(3), 167-177. https://doi.org/10.19173/irrodl.v18i3.3250

Canals, L., Burkle, M., \& Nørgård, R. T. (2019). Universities of the future: Several perspectives on the future of higher education. International Journal of Educational Technology in Higher Education. Retrieved from https://educationaltechnologyjournal.springeropen.com/universitiesofthefuture

Clow, D. (2013). An overview of learning analytics. Teaching in Higher Education, 18(6), 683-695. https://doi.org/10.1080/13562517.2013.827653

Collins, A., \& Halverson, R. (2018). Rethinking education in the age of technology: The digital revolution and schooling in America. Teachers College Press.

Daniel, J., Cano, E. V., \& Cervera, M. G. (2015). The future of MOOCs: Adaptive learning or business model? International Journal of Educational Technology in Higher Education, 12(1), 64-73. https://doi.org/10.7238/rusc.v12i1.2475

Delgado, A., Wardlow, L., O’Malley, K., \& McKnight, K. (2015). Educational technology: A review of the integration, resources, and effectiveness of technology in K-12 classrooms. Journal of Information Technology Education: Research, 14, 397-416. https://doi.org/10.28945/2298

Drachsler, H., \& Greller, W. (2016). Privacy and analytics - it's a DELICATE issue. A checklist for trusted learning analytics. In The Sixth International Learning Analytics \& Knowledge Conference (pp. 89-98). ACM. https://doi.org/10.1145/2883851.2883893

Gašević, D., Dawson, S., \& Siemens, G. (2015). Let 's not forget: Learning analytics are about learning. TechTrends, 59(1), 64-71.

Giurgiu, L. (2017). Microlearning: An evolving elearning trend. Scientific Bulletin, 22(1), 18-23. https://doi.org/10.1515/bsaft-2017-0003

Gordon, N. (2014). Flexible pedagogies: Technology-enhanced learning Contents. York: Higher Education Academy.

Hill, C. B., Guthrie, K. M., \& Kurzweil, M. (2018). Technology in higher education: Reflections from the Bowen Colloquium on higher education leadership. USA: Ithaka S+R. https://doi.org/10.18665/sr.306629

International, T. S., Analytics, L., \& Conference, K. (2016). The Sixth International Learning Analytics \& Knowledge Conference Edinburgh, United Kingdom Supported by:

Isaías, P. (2018). Model for the enhancement of learning in higher education through the deployment of emerging technologies. Journal of Information, Communication and Ethics in Society, 16(4), 401-412. https://doi.org/10.1108/JICES-04-2018-0036

Jomah, O., Amamer, K. M., Kishore, X. P., \& Aurelia, S. (2016a). Micro learning: A modernized education system. BRAIN - Broad Research in Artificial Intelligence and Neuroscience, 7(1), 103-110. Retrieved from http://doi.wiley.com/10.1002/cbe2.1032

Jomah, O., Amamer, K. M., Kishore, X. P., \& Aurelia, S. (2016b). Micro learning: A modernized education system. BRAIN - Broad Research in Artificial Intelligence and Neuroscience, 7(1), 103-110.

King, E., \& Boyatt, R. (2014). Exploring factors that influence adoption of e-learning within higher education. 
British Journal of Educational Technology, 46(6), 1272-1280. https://doi.org/10.1111/bjet.12195

Li, K. C., Wong, T. L., Cheung, S. K. S., Lam, J., \& Ng, K. K. (Eds.). (2014). Technology in education: Transforming educational practices with technology. In First International Conference, ICTE 2014. Hong Kong: Springer. https://doi.org/10.1007/978-3-662-46158-7

Majuri, J., Koivisto, J., \& Hamari, J. (2018). Gamification of education and learning: A review of empirical literature. In 2nd International GamiFIN Conference (GamiFIN 2018) (pp. 11-19). Pori, Finland.

Ng'ambi, D., Brown, C., Bozalek, V., Gachago, D., \& Wood, D. (2016). Technology enhanced teaching and learning in South African higher education - A rearview of a 20 year journey. British Journal of Educational Technology, 47(5), 843-858.

OECD. (2019). Centre for Educational Research and Innovation (CERI) - E-learning in post-secondary education and training. Retrieved May 1, 2019, from http://www.oecd.org/education/research/centreforeducationalresearchandinnovationceri-e-learninginpost-secondaryeducationandtraining.htm

Oliveira, P. C. D., Cunha, C. J. C. D. A., \& Nakayama, M. K. (2016). Learning Management Systems (LMS) and e-learning management: An integrative review and research agenda. JISTEM-Journal of Information Systems and Technology Management, 13(2), 157-180. https://doi.org/10.4301/S1807-17752016000200001

Özyurt, Ö., \& Özyurt, H. (2015). Learning style based individualized adaptive e-learning environments: Content analysis of the articles published from 2005 to 2014. Computers in Human Behavior, 52, 349-358. https://doi.org/10.1016/j.chb.2015.06.020

Rai, L., \& Chunrao, D. (2016). Influencing factors of success and failure in MOOC and general analysis of learner behavior. International Journal of Information and Education Technology, 6(4). https://doi.org/10.7763/IJIET.2016.V6.697

Salmon, G. (2014). Learning innovation: A framework for transformation. European Journal of Open, Distance and e-Learning, 17(2), 220-236. https://doi.org/10.2478/eurodl-2014-0031

Sandanayake, T. C. (2019). Promoting open educational resources-based blended learning. International Journal of Educational Technology in Higher Education, 16(3). https://doi.org/10.1186/s41239-019-0133-6

Sclater, N., Peasgood, A., \& Mullan, J. (2016). Learning analytics in higher education. London, UK: Jisc.

Straub, E. T. (2009). Understanding technology adoption: Theory and future directions for informal learning. Review of Educational Research, 79(2), 625-649. https://doi.org/10.3102/0034654308325896

Truong, H. M. (2016). Integrating learning styles and adaptive e-learning system: Current developments, problems and opportunities. Computers in Human Behavior, 55, 1185-1193. https://doi.org/10.1016/j.chb.2015.02.014

Tseng, S., Tsao, Y., Yu, L., Chan, C., \& Lai, K. (2016). Who will pass? Analyzing learner behaviors in MOOCs. Research and Practice in Technology Enhanced Learning, 11(8). https://doi.org/10.1186/s41039-0160033-5

Ustundag, A., \& Cevikcan, E. (2017). Industry 4.0: Managing the digital transformation. Springer. 